\title{
Long term soil moisture mapping over the Tibetan plateau using Special Sensor Microwave/Imager
}

\author{
R. van der Velde ${ }^{1}$, M. S. Salama ${ }^{1}$, T. Pellarin ${ }^{2}$, M. Ofwono ${ }^{1, *}$, Y. Ma $^{3}$, and Z. Su ${ }^{1}$ \\ ${ }^{1}$ Faculty of ITC, University of Twente, Enschede, the Netherlands \\ ${ }^{2}$ Centre National de la Recherche Scientifique, Laboratoire d'études des Transferts en Hydrologie et Environnement, \\ Grenoble, France \\ ${ }^{3}$ Key Laboratory of Tibetan Environment Changes and Land Surface Processes, Institute of Tibetan Plateau Research, \\ Chinese Academy of Science (ITP/CAS), Beijing, P.R. China \\ *now at: Institute of Geodesy and Cartography (IGIK), Department of Remote Sensing, Warsaw, Poland
}

Correspondence to: R. van der Velde (r.vandervelde@utwente.nl)

Received: 14 April 2013 - Published in Hydrol. Earth Syst. Sci. Discuss.: 29 May 2013

Revised: 4 February 2014 - Accepted: 22 February 2014 - Published: 4 April 2014

\begin{abstract}
This paper discusses soil moisture retrievals over the Tibetan Plateau from brightness temperature $\left(T_{\mathrm{B}}\right.$ 's) observed by the Special Sensor Microwave Imagers (SSM/I's) during the warm seasons of the period from July 1987 to December 2008. The Fundamental Climate Data Record (FCDR) of F08, F11 and F13 SSM/I satellites by the Precipitation Research Group of Colorado State University is used for this study. A soil moisture retrieval algorithm is developed based on a radiative transfer model that simulates top-of-atmosphere $T_{\mathrm{B}}$ 's whereby effects of atmosphere are calculated from near-surface forcings obtained from a bias-corrected dataset. Validation of SSM/I retrievals against in situ measurements for a two-and-half year period (225 matchups) gives a Root Mean Squared Error of $0.046 \mathrm{~m}^{3} \mathrm{~m}^{-3}$. The agreement between retrievals and Noah simulations from the Global Land Data Assimilation System is investigated to further provide confidence in the reliability of SSM/I retrievals at the Plateau-scale.

Normalised soil moisture anomalies $(N)$ are computed on a warm seasonal (May-October) and on a monthly basis to analyse the trends present within the products available from July 1987 to December 2008. The slope of linear regression functions between $N$ and time is used to quantify the trends. Both the warm season and monthly $N$ indicate severe wettings of 0.8 to almost 1.6 decade $^{-1}$ in the centre of the Plateau. Correlations are found by the trend with elevation for the warm season as a whole and the individual months May, September and October. The observed
\end{abstract}

wetting of the Tibetan Plateau agrees with recent findings on permafrost retreat, precipitation increase and potential evapotranspiration decline.

\section{Introduction}

The importance of the Tibetan Plateau for the atmospheric circulation and the development of large-scale weather systems over the Asian continent has been widely acknowledged (e.g. Lau et al., 2006; Yanai and Wu, 2006). Due to its wide extent and high elevation $(<3500 \mathrm{~m}$ above sea level, a.s.l.), the Plateau plays a critical role in directing moist air from the eastern Indian Ocean and Bay of Bengal towards central China. Interactions with other large-scale circulation systems, such as the southeasterly flow from the South China Sea, can result in persistent wet (or dry) patterns over East Asia (Xu et al., 2008). This flow of moist air from oceans and seas is also affected by heat and moisture sources from the Plateau, which creates the so-called "air pump" influencing the onset and maintenance of the Asian monsoon (Wu et al., 2007).

In a changing climate, global warming will increasingly affect the partitioning of radiation into sensible and latent heat over the Plateau and, thus, the Tibetan air pump. In the 2007 IPCC (Intergovernmental Panel on Climate Change) report, the observed and projected impact of climate change at a global scale has been documented (Solomon et al., 2007). 
However, the effects of climate change at a regional scale can be much more complex. Particularly high-altitude regions, such as the Tibetan Plateau, are expected to be more sensitive because of the snow-feedback (Giorgi et al., 1997).

An important land surface state variable controlling interactions between the land surface and atmosphere is soil moisture (Koster et al., 2004). Being highly variable in both space and time, it is not feasible to base large-scale soil moisture monitoring on in situ measurements. Various remote-sensing techniques have, therefore, been explored for their potential of monitoring soil moisture (e.g. Dubois et al., 1995; Jackson et al., 1999; Wagner and Scipal, 2000; Njoku et al., 2003; Su et al., 2003). Datasets collected by microwave instruments operating at L-band $(\sim 1.4 \mathrm{GHz})$ have been proven to be superior for retrieving top soil moisture over a wide range of vegetated conditions (Jackson and Schmugge, 1989). This resulted in the formulation of missions carrying L-band microwave sensors for soil moisture monitoring, of which the SMOS (Soil Moisture and Ocean Salinity, Kerr et al., 2001) and NASA's Aquarius missions have been launched recently, and the SMAP (Soil Moisture Active Passive, Entekhabi et al., 2010) mission is expected to follow in the foreseeable future with its expected launch date in the second half of 2014.

Despite being less favourable, various studies have also found soil moisture sensitivity at the higher frequencies (e.g. Jackson, 1997; Paloscia et al., 2001; Wen et al., 2005; Gao et al., 2006). A disadvantage of the high frequencies is that contributions from the atmosphere and vegetation have a strong masking effect on the surface emission (e.g. Drusch et al., 2001). However, these disturbances are expected to be less severe over the Tibetan Plateau as compared to most other regions. The amount of atmosphere and atmospheric water vapour contributing to the microwave emission is smaller at the elevation of the Plateau ( $>3500$ m a.s.l). Moreover, the harsh Tibetan environment sustains only sparse vegetation even at peak biomass (Van der Velde and Su, 2009). Therefore, some success in retrieving soil moisture from high frequency passive microwave observations can be expected for the Tibetan Plateau after correcting for the vegetation and atmospheric effects.

For instance, Wen et al. (2003) have used the Tropical Rainfall Measuring Mission (TRMM) Microwave Imager (TMI) datasets for retrieving soil moisture and validated their results against soil moisture measured during one-month. The datasets collected by the TMI and the later launched Advanced Microwave Scanning Radiometer (AMSR)-E are, however, too short to permit drawing any conclusions regarding climate change. Long term records of passive microwave measurements are available from the Special Sensor Microwave Imager (SSM/I), which has been facilitated through the Defence Meteorological Satellite Programme (DMSP). At a given time, typically three SSM/I instruments have been operational since 1987. This ensured an almost daily coverage near the equator for a period of more than 25 years.
In this paper, we use the Fundamental Climate Data Record (FCDR) of SSM/I data developed by Semunegus et al. (2010) for the period July 1987 till December 2008 for retrieving soil moisture over the Tibetan Plateau. The retrieval algorithm is developed based on a radiative transfer model that simulates top-of-atmosphere (TOA) brightness temperatures $\left(T_{\mathrm{B}}\right.$ 's). Land surface contributions are taken into account via the well-known $\tau$ - $\omega$ model (Mo et al., 1982) and atmospheric effects are considered as in Kerr and Njoku (1990), for which the parameterization of Pellarin et al. $(2003,2006)$ is applied with input of the bias-corrected atmospheric forcings developed by Sheffield et al. (2006).

The soil moisture and vegetation transmissivity (or optical depth) are inverted simultaneously from the horizontally $(\mathrm{H})$ and vertically $(\mathrm{V})$ polarized $19.4 \mathrm{GHz} T_{\mathrm{B}}$ 's, whereby the effective temperature $\left(T_{\text {eff }}\right)$ is obtained from the atmosphere corrected V polarized $37 \mathrm{GHz}$ channel. This setup avoids the use of ancillary information needed by previously developed algorithms (e.g. Drusch et al., 2001; Wen et al., 2005; Gao et al., 2006) to correct for vegetation and surface temperature, which may not be available (or reliable) for the extreme Tibetan conditions. Hence, the applied algorithm has similarities with the Land Parameter Retrieval Model (LPRM) described in Owe et al. (2008) and the inversion approach used in Jackson et al. (2002). The advantage of the algorithm formulated here is that the effects of the atmosphere are explicitly accounted for. It should, however, be noted that it is not our objective to present an alternative for global soil moisture monitoring.

The retrieval results are validated using soil moisture measured in situ at four locations on the central part of the Tibetan Plateau in the period from August 2005 to December 2008. An additional comparison across the Plateau is made with the soil moisture simulations by Noah Land Surface Model (LSM) via the Global Land Data Assimilation System (GLDAS, Rodell et al., 2004). The soil moisture retrievals from July 1987 to December 2008 are used to investigate the trends of the standardised anomalies and their dependence upon season as well as elevation. We determine where the soil moisture changes occur, how much these changes are and during which time of the year these changes are most prominent.

\section{Study area and dataset}

\subsection{Description of the study area}

The Tibetan Plateau is situated in the western part of China at $80-105^{\circ} \mathrm{E}$ and $28-37^{\circ} \mathrm{N}$ as shown in Fig. 1. With an average altitude of about $4000 \mathrm{~m}$ a.s.l., it is the highest plateau in the world and embraces many mountain ranges with peaks well above $6000 \mathrm{~m}$ a.s.l. According to the University of Maryland $1 \mathrm{~km}$ global land cover classification (Hansen et al., 1998, see Fig. 2), a mixture of bare ground and open shrubland 


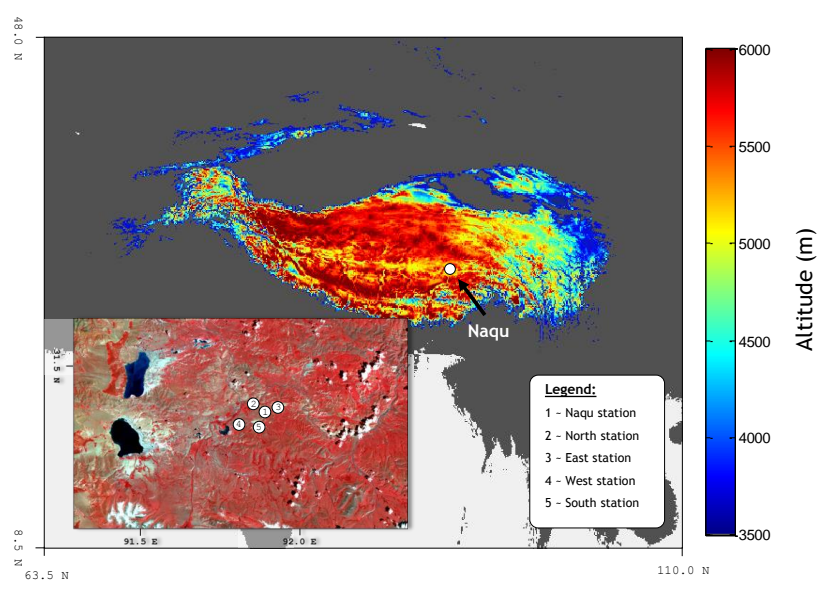

Fig. 1. The elevation of areas $>3500 \mathrm{~m}$ a.s.l., representing the Tibetan Plateau, is indicated by the GTOPO30 digital elevation model, land below $3500 \mathrm{~m}$ is shown as grey and water (oceans and seas) is white. Within a subset of LandSat TM false colour image covering part of the Naqu river basin, the location of the soil moisture/temperature station are shown.

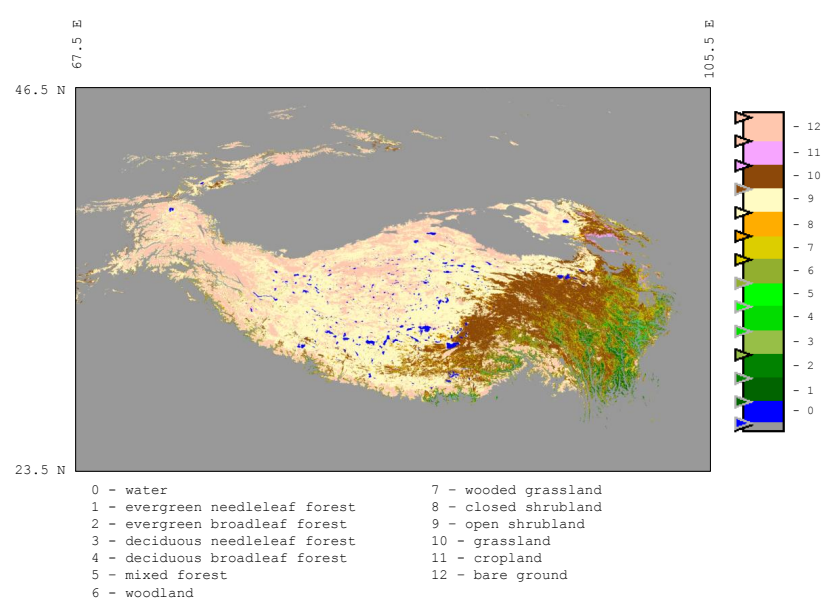

Fig. 2. Land cover classification of the Tibetan Plateau after the University of Maryland $1 \mathrm{~km}$ global land cover classification (Hansen et al., 1998).

dominates the Plateau. This shifts in the east from grassland towards more densely vegetated land covers in the far east, namely wooded grassland, woodland.

Weather on the Plateau is strongly affected by the Asian Monsoon reaching its peak intensity in the months July, August and September. During this three-month period, moist air enters the Plateau from the lower elevated southeastern part and crosses gradually towards the areas with a higher elevation in the western part of the plateau (e.g. Yanai and $\mathrm{Wu}, 2006)$. As a result, the total amount of precipitation decreases from east to west with up to $900 \mathrm{~mm}$ rain measured in the southeast and only up to $60 \mathrm{~mm}$ rain measured in the far west (Zhao et al., 2004). Typically, more than $80 \%$ of the
Table 1. SSM/I sensor characteristics and platforms.

\begin{tabular}{lrr}
\hline $\begin{array}{l}\text { Frequency } \\
(\mathrm{GHz})\end{array}$ & Polarization & $\begin{array}{r}\text { Footprint } \\
\text { size }(\mathrm{km})\end{array}$ \\
\hline 19.4 & $\mathrm{H}$ and V & $69 \times 43$ \\
22.2 & $\mathrm{~V}$ & $50 \times 40$ \\
37.0 & $\mathrm{H}$ and V & $37 \times 28$ \\
85.5 & $\mathrm{H}$ and V & $15 \times 13$ \\
\hline & & Ascending \\
& Data & $\begin{array}{r}\text { crossing time } \\
\text { at the equator } \\
\end{array}$ \\
Satellite & availability & (UTC) \\
\hline F08 & Jul. 1987-Dec. 1991 & $06: 12$ \\
F11 & Dec. 1991-May 1995 & $18: 11$ \\
F13 & May 1995-Dec. 2008 & $17: 42$ \\
\hline
\end{tabular}

precipitation is measured as rain during the monsoon. The winter months, from November to April, are dominated by dry and cold conditions with temperatures generally below freezing point. Little precipitation occurs in this period either in a liquid or a frozen state as snow resulting in fairly low soil moisture dynamics in both time and space (Van der Velde et al., 2008). The coldest month is January with a mean monthly air temperature of $-10.3{ }^{\circ} \mathrm{C}$ and the warmest month is July with a mean monthly air temperature of $15.0^{\circ} \mathrm{C}$.

\subsection{SSM/I instruments}

The SSM/I is a conical scanning microwave radiometer operating from a view angle of about $53^{\circ}$ and frequencies of 19.4, 22.2, 37.0 and $85.5 \mathrm{GHz}$. For all frequencies, except the $22.2 \mathrm{GHz}, \mathrm{SSM} / \mathrm{I}$ measures brightness temperatures ( $T_{\mathrm{B}}$ 's) in both $\mathrm{H}$ and $\mathrm{V}$ polarizations resulting in a total of seven channels. Table 1 summarizes the instrument parameters of $\mathrm{SSM} / \mathrm{I}$ and additional information can be found in Hollinger et al. (1990). Since 1987, more than one SSM/I instrument has been operational for many episodes supported by the Defence Meteorological Satellite Programme (DMSP). The satellites from which the SSM/I data has been utilised for this study are listed in Table 1.

The SSM/I datasets used for this study were made available by the Precipitation Research Group of Colorado State University (http://rain.atmos.colostate.edu, last access: 11 March 2013), which were resampled to a $0.25^{\circ}$ spatial resolution using a nearest neighbourhood technique. They have developed in collaboration with NOAA's National Climatic Data Center a suite of screening techniques for harmonization of the radiometric and geometric data quality across the SSM/I sensors for the development of a Fundamental Climate Data Record (FCDR). Some of the issues addressed (Semunegus et al., 2010) are inter-sensor calibration, cross-track bias corrections, orbital drift and navigational inaccuracies. 
It is well-known that for retrieving soil moisture, the soil surface and vegetation should be in thermal equilibrium (e.g. Jackson and Hsu, 2001; Jackson et al., 1997). These conditions occur typically during sunrise. Therefore, only the morning passes have been selected for this study. Further, it should be noted that for each period the SSM/I data from a single satellite has been used. From July 1987 till December 1991 ascending F08 passes are used; from December 1991 till January 1996 the descending F11 passes are used and from January 1996 to December 2008 the descending F13 passes are used.

\subsection{In situ measurements}

The soil moisture retrieved from the SSM/I observations are validated with in situ measurements collected in the Naqu river basin located on the central part of the Tibetan Plateau as depicted in Fig. 1. The elevation in this region is $4500 \mathrm{~m}$ a.s.l. and the hilltops reach heights just above $5000 \mathrm{~m}$. The land cover is dominated by wetlands in the depressions of land surface and grasslands consisting of short prairie grasses and mosses situated at a higher elevation (Van der Velde et al., 2009).

About $25 \mathrm{~km}$ southwest of Naqu city is one of the key meteorological stations $\left(91.8987^{\circ} \mathrm{E}, 31.3686^{\circ} \mathrm{N}, \mathrm{WSG} 84\right)$ of the mesoscale network installed as a part of Global Energy and Water cycle Experiment (GEWEX) supported field campaigns; hereafter referred to as Naqu station. A comprehensive set of instruments measures at Naqu station water and energy exchanges between land surface and atmosphere (Ma et al., 2006). Four additional soil moisture/temperature stations were installed within $10 \mathrm{~km}$ of Naqu station during the 2006 summer (16-27 July 2006). The soil moisture stations have been placed north, south, west and east of Naqu station as shown in Fig. 1. Grasslands dominate the land cover at the north, west, east and Naqu stations and south station is located in a wetland.

The instrumentation used for these stations consists of an EM5b data logger with five $10 \mathrm{~cm}$ long ECH2O (type: EC-10) capacitance probes for measuring soil moisture all manufactured by Decagon Devices. At each station, probes have been installed horizontally at depths of 2.5, 7.5, 15.0, 30.0 and $60.0 \mathrm{~cm}$. The EC-10 readings have been calibrated using gravimetrically determined volumetric soil moisture to an estimated accuracy of $0.029 \mathrm{~m}^{3} \mathrm{~m}^{-3}$ (Van der Velde et al., 2012). This uncertainty level is in line with the reliability of soil moisture probe products previously reported in Cosh et al. (2005) and Joseph et al. (2010). Readers are referred to Su et al. (2011) for additional information on the soil moisture stations and data.

\section{Soil moisture retrieval}

\subsection{Microwave emission model}

The algorithm developed for soil moisture retrieval is based on a semi-empirical microwave emission model that considers the radiative transfer processes along the soil-vegetationatmosphere pathways (Kerr and Njoku, 1990). Following to this concept the $T_{\mathrm{B}}$ observed at the TOA can be computed as

$$
\begin{aligned}
T_{\mathrm{B}}^{p}=T_{\mathrm{a}}^{\uparrow} & +\gamma_{\mathrm{a}}\left(1-e_{\mathrm{s}}^{p}\right) \gamma_{\mathrm{v}}^{p}\left(T_{\mathrm{a}}^{\downarrow}-\gamma_{\mathrm{a}} T_{\mathrm{cos}}\right)+\gamma_{\mathrm{a}} e_{\mathrm{s}}^{p} \gamma_{\mathrm{v}}^{p} T_{\mathrm{s}} \\
& +\gamma_{\mathrm{a}}\left(1-\omega^{p}\right)\left(1-\gamma_{\mathrm{v}}^{p}\right)\left(1+\left(1-e_{\mathrm{s}}^{p}\right) \gamma_{\mathrm{v}}^{p}\right) T_{\mathrm{v}}
\end{aligned}
$$

where, $T_{\mathrm{a}}^{\downarrow}$ and $T_{\mathrm{a}}^{\uparrow}$ are respectively the down- and upward emitted atmospheric temperatures $(\mathrm{K}), \gamma_{\mathrm{a}}$ and $\gamma_{\mathrm{v}}$ are respectively the transmissivity of the atmosphere and the vegetation layer $(-), \omega$ is the single scattering albedo of the vegetation layer, $T_{\mathrm{S}}$ and $T_{\mathrm{v}}$ are respectively the soil and canopy temperatures $(\mathrm{K}), e_{\mathrm{S}}$ is the soil surface emissivity, $T_{\cos }$ is the cosmic background $(=2.7 \mathrm{~K})$, and $p$ indicates the polarization, which can either be horizontal or vertical.

The emissivity of the soil surface, related via Kirchhoff's law to its reflectivity, is influenced by the roughness that can be corrected for through application of the model by Wang and Choudhury (1981)

$e_{\mathrm{s}}^{p}=1-\left[(1-Q) R_{0}^{p}+Q R_{0}^{q}\right] \exp \left(-k^{2} s^{2} \cos ^{2} \theta_{\mathrm{v}}\right)$

where, $R_{0}$ is the Fresnel (or smooth surface) reflectivity, $s$ is the standard deviation of the surface height $(\mathrm{cm})$, and $k$ is the wave number $\left(\mathrm{cm}^{-1}\right), \theta_{\mathrm{v}}$ is the view angle (degrees) and $q$ is the polarization orthogonal to polarization $p$. It should be noted that $k^{2} s^{2}$ is typically represented by a single effective roughness parameter, $h$, and the $Q$ quantifies the depolarizing effects of surface roughness.

\subsection{Algorithm}

Retrieving soil moisture based on the radiative transfer approach formulated by Eqs. (1) and (2) needs an algorithm that accounts for the unknowns either via assumptions or an iterative procedure. We start with assuming the soil surface and canopy temperature equal to each other, which permits using an effective temperature ( $\left.T_{\text {eff }}\right)$. This can be justified because, as mentioned above, both media are typically in thermal equilibrium near dawn. The $T_{\text {eff }}$ is estimated from the $\mathrm{V}$ polarized $37 \mathrm{GHz}$ channel as is further elaborated on in Sect. 3.3.

For the $\omega$ and the roughness parameters, $h$ and $Q$, several studies have previously used fixed values. As such, we adopt in accordance with Jackson et al. (2002) for the $\omega$ a value of 0.05 for $\mathrm{V}$ polarization and assume the $\mathrm{H}$ polarized $\omega$ equal to 0.00 . Further, the surface roughness parameterization proposed by Njoku and Li (1999) has been used, which includes values of 0.14 and 0.12 for the $h$ and $Q$, respectively. 
As for the atmospheric variables, a modified version of the method developed by Pellarin et al. (2003) has been employed. This method quantifies the atmosphere opacity $\left(\tau_{\mathrm{a}}\right)$ and equivalent air temperature $\left(T_{\mathrm{a}}^{\mathrm{eq}}\right)$ using near-surface meteorological variables and the elevation of the land surface. The same procedure and global dataset as described in Pellarin et al. (2006) have been used for development of the expressions for the SSM/I frequencies, 19.3 and $37.0 \mathrm{GHz}$, which results for the $\tau_{\mathrm{a}}$ in

$$
\begin{aligned}
\tau_{\mathrm{a}(19.3 \mathrm{GHz})} & =\exp (-5.2138-0.2176 \cdot Z \\
& \left.+0.00479 \cdot T_{\mathrm{a}}+0.1242 \cdot Q_{\mathrm{a}}\right) \\
\tau_{\mathrm{a}(37.0 \mathrm{GHz})} & =\exp (-2.6992-0.2312 \cdot Z \\
& \left.+0.00108 \cdot T_{\mathrm{a}}+0.0673 \cdot Q_{\mathrm{a}}\right)
\end{aligned}
$$

where, $T_{\mathrm{a}}$ is the air temperature at surface level $(\mathrm{K}), Q_{\mathrm{a}}$ is the specific humidity at surface level $\left(\mathrm{g} \mathrm{kg}^{-1}\right), Z$ is the elevation (km).

Since frequency (or wavelength) was found not to have an effect on $T_{\mathrm{a}}^{\mathrm{eq}}$, the same expression as given in Pellarin et al. (2006) is used here

$T_{\mathrm{a}}^{\mathrm{eq}}=\exp \left(4.8716+0.002447 \cdot T_{\mathrm{a}}\right)$

The frequency dependent $\tau_{\mathrm{a}}$ is used to compute the transmittance of the atmosphere $\left(\gamma_{\mathrm{a}(\mathrm{fr})}\right)$ as $\exp \left(-\tau_{\mathrm{a}(\mathrm{fr})} \sec \theta\right)$, which is subsequently employed for the calculation of $T_{\mathrm{a}}^{\downarrow}$ as $T_{\mathrm{a}}^{\mathrm{eq}}(1-$ $\gamma_{\mathrm{a}(\mathrm{fr})}$ ) where (fr) indicate the frequency dependence of the variable.

The specific humidity $\left(Q_{\mathrm{a}}\right)$ and air temperature $\left(T_{\mathrm{a}}\right)$ needed as inputs are obtained from the bias corrected reanalysis datasets described in Sheffield et al. (2006). Further, the GTOPO30 Digital Elevation Model (DEM) is used for the elevation. The Sheffield datasets are resampled to the SSM/I grid by using a nearest-neighbour method and the DEM by averaging all GTOPO30 elevations within each SSM/I pixel.

The two remaining unknowns are the vegetation transmittance $\left(\gamma_{\mathrm{v}}\right)$, defined as function of its opacity $\left(\tau_{\mathrm{v}}\right)$ as $\gamma_{\mathrm{v}}=$ $\exp \left(-\tau_{\mathrm{v}} \sec \theta\right)$, and the dielectric constant $(\varepsilon)$ related to soil moisture via a dielectric mixing model and soil texture information. Assuming polarization independence of the $\gamma_{v}$ reduces the problem to finding a solution for two equations with two unknowns to which the SSM/I $19.4 \mathrm{GHz} \mathrm{H}$ and $\mathrm{V}$ polarized $T_{\mathrm{B}}$ 's are input. Here, the $\gamma_{\mathrm{v}}$ and the $\varepsilon$ are inverted by minimising the absolute difference between the modelled and SSM/I measured $19.4 \mathrm{GHz} \mathrm{H}$ and V polarized $T_{\mathrm{B}}$ 's using a least squares optimisation routine. The retrieved $\varepsilon$ is converted into the soil moisture content using the mixing model by Dobson et al. (1985) and soil texture information obtained from $5 \mathrm{~min}$ (about $10 \mathrm{~km}$ ) resolution global soil texture map (Reynolds et al., 2000). We assume, thus, that the Dobson mixing model developed using laboratory measurements taken at $18 \mathrm{GHz}$ can also be applied to the $19.4 \mathrm{GHz}$ SSM/I bands. Previously, Jackson et al. (2002) have applied a similar approach successfully to SSM/I data collected over the Southern Great Plains. Moreover, the dualchannel iterative algorithm is considered as one of the candidates for delivering the SMAP radiometer soil moisture products (Moghaddam et al., 2011).

\subsection{Effective temperature estimation}

An important input to the retrieval algorithm is the temperature of the layer contributing to the microwave emission; commonly referred to as the effective temperature $\left(T_{\text {eff }}\right)$. For the lower microwave frequencies, the emitting layer consists of the canopy and the soil volume from which the surface emission is generated. The thickness of the contributing soil layer is considered to be less than the wavelength (e.g. De Jeu and Owe, 2003), which is for the SSM/I $19.4 \mathrm{GHz}$ channel about $1.55 \mathrm{~cm}$. Near dawn, however, not only a thermal equilibrium between canopy and soil surface often prevails, but also soil temperature gradients near the surface are small (e.g. Choudhury, 1993; Van der Velde et al., 2009). These two assumptions have previously been used to justify estimating $T_{\text {eff }}$ based on a linear relationship between the $\mathrm{V}$ polarized $37 \mathrm{GHz} T_{\mathrm{B}}$ and the soil (or surface) temperature (e.g. Holmes et al., 2009).

The linear relationship between $T_{\text {eff }}$ and $\mathrm{V}$ polarized $37 \mathrm{GHz} T_{\mathrm{B}}$ implies that the emissivity at the respective sensing configuration (frequency, polarization and incidence angle) is assumed constant. Owe and Van de Griend (2001) have shown that this assumption holds for $\mathrm{V}$ polarized $37 \mathrm{GHz} T_{\mathrm{B}}$ measured specifically from the large view angles of the SSM/I's. At those angles, the theoretical V polarized smooth surface (Fresnel) reflectivity approaches zero and has a limited sensitivity to land surface states (e.g. soil moisture, vegetation). Here, we adopt a comparable approach and utilise the monthly climatology of the decadal emissivity database developed by Prigent et al. (2006). Advantage of using the monthly emissivity is that through Eqs. (1), (4) and (5) the atmosphere effects can be considered.

\section{Assessment of SSM/I retrievals}

The algorithm has been applied as formulated above for retrieving soil moisture from the FCDR SSM/I $T_{\mathrm{B}}$ 's collected in the period July 1987 to December 2008. Figure 3 shows a diagram with an overview of this procedure for obtaining the satellite products. To filter out the pixels most severely affected by precipitation, frozen soil and snow, only retrievals are considered that are obtained with a residual mean absolute error (MAE) of less than $0.2 \mathrm{~K}$ between the observed and computed $T_{\mathrm{B}}$ 's for the two polarizations, defined here as,

$\mathrm{MAE}=\frac{1}{2}\left(\left|T_{\mathrm{B}, \mathrm{c}}^{\mathrm{H}}-T_{\mathrm{B}, \mathrm{sat}}^{\mathrm{H}}\right|+\left|T_{\mathrm{B}, \mathrm{c}}^{\mathrm{V}}-T_{\mathrm{B}, \mathrm{sat}}^{\mathrm{V}}\right|\right)$

where, subscripts ${ }_{c}$ and ${ }_{\text {sat }}$ indicate that the variable represents respectively the calculated and SSM/I $T_{\mathrm{B}}$. This is equivalent to error component attributable to uncertainties 


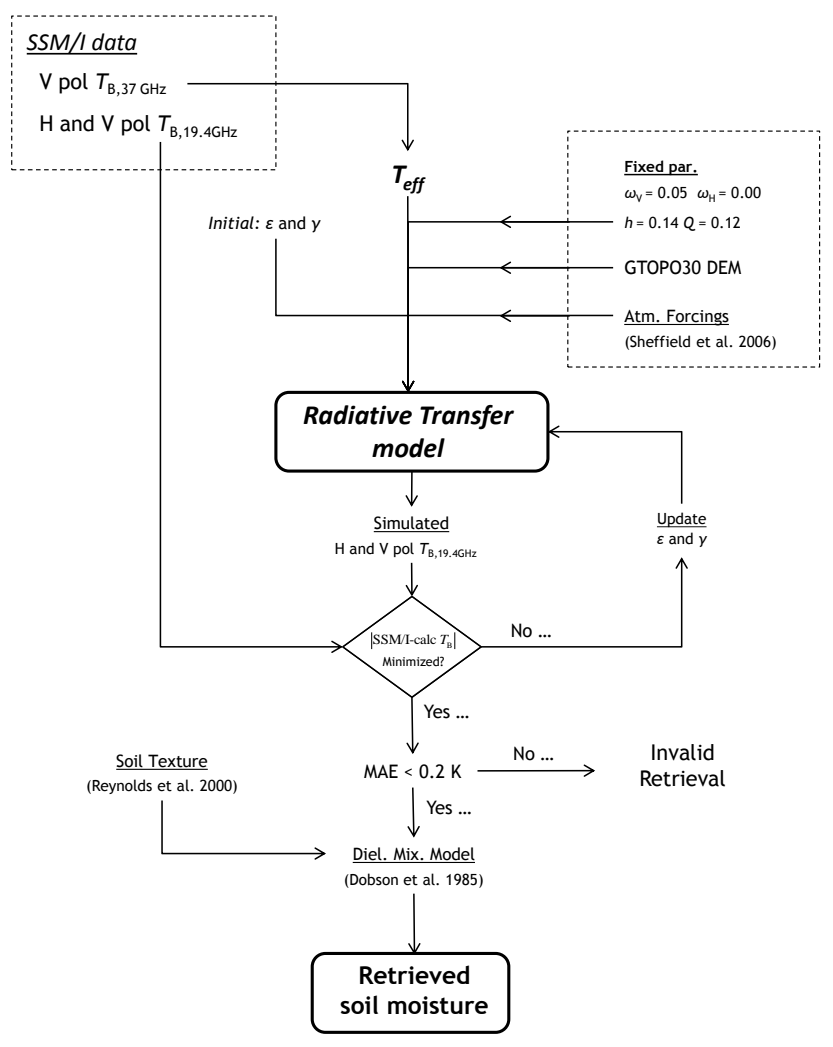

Fig. 3. Overview of the algorithm and procedures adopted for derivation of the soil moisture products from the SSM/I observations.

associated with the earth incidence angle calculation (Berg et al., 2013).

\subsection{Observed soil moisture and vegetation optical depth climatology}

A first assessment is performed via analysis of the monthly climatology of the retrieved soil moisture and optical depth $\left(\tau_{\mathrm{v}}\right)$ derived from the vegetation transmittance. The climatologies are obtained by averaging the monthly means on a pixel basis over the complete period. Pixels are included in the analysis when monthly values are available for at least fifteen (non-consecutive) of in total twenty-two years and the monthly means are based on a minimum of five valid retrievals. This implies for soil moisture that the monthly mean is estimated with an accuracy of $0.03 \mathrm{~m}^{3} \mathrm{~m}^{-3}$ with $90 \%$ confidence for the $75 \%$ of the pixels. The resulting soil moisture and optical depth climatologies are shown in Figs. 4 and 5 for the months May to October. The winter months are excluded here because too few retrievals are available to fulfil the above criterions, which is already visible in the May and October climatologies. Further the optical depth climatologies are displayed for visualization purposes as differences between the climatology of August and the respective month.

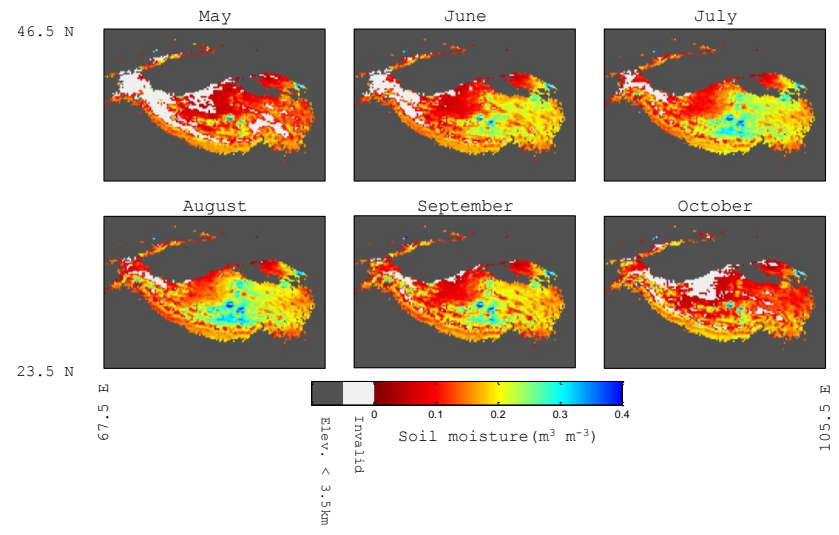

Fig. 4. 1987-2008 soil moisture climatology for the months May to October derived from SSM/I observations.

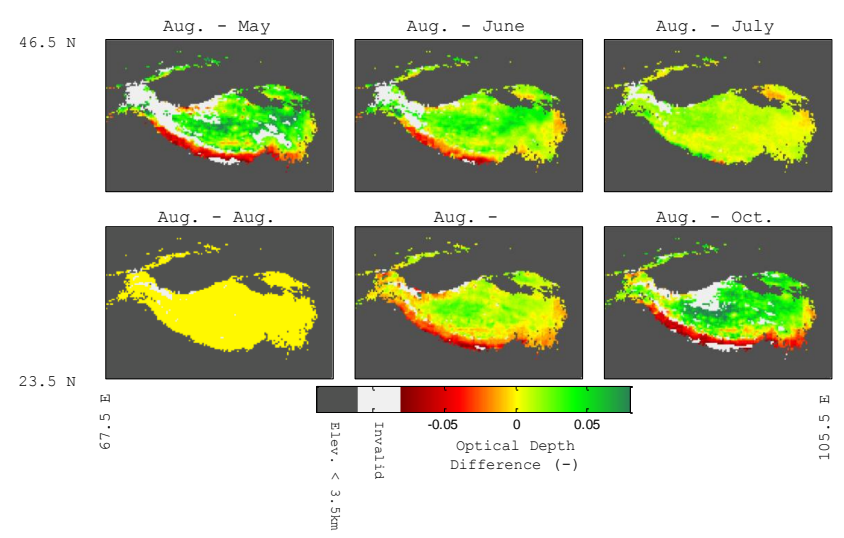

Fig. 5. Difference between the 1987-2008 SSM/I retrieved optical depth climatology of August and the months May to October, respectively.

The overall dynamics in the observed soil moisture and vegetation optical depth climatologies agree with our general understanding of the Tibetan land surface conditions during the Asian Monsoon. An initial large scale wetting is observed in June in the eastern and central part of the Plateau. The extent of those areas with elevated soil moisture levels $\left(>0.10 \mathrm{~m}^{3} \mathrm{~m}^{-3}\right)$ further increases and spreads towards the west in July and August, reduces again in September and is almost back at winter levels in October. Several areas are noted with consistently high soil moisture values throughout the year, which can be associated with the presence of lakes. Soils in the proximity of lakes are typically wet, which explains in combination with the low emissivity of open water itself the high soil moisture retrievals. The Nam-Tso and Silling-Tso lakes can be identified in the centre, whereas the Qinghai lake is recognisable in the northeast.

Although less obvious with optical depth difference up to $0.1(-)$, the monthly optical depth climatology displays a seasonal dependence similar to the one observed for soil moisture. In July and August, the highest optical depths with peak 


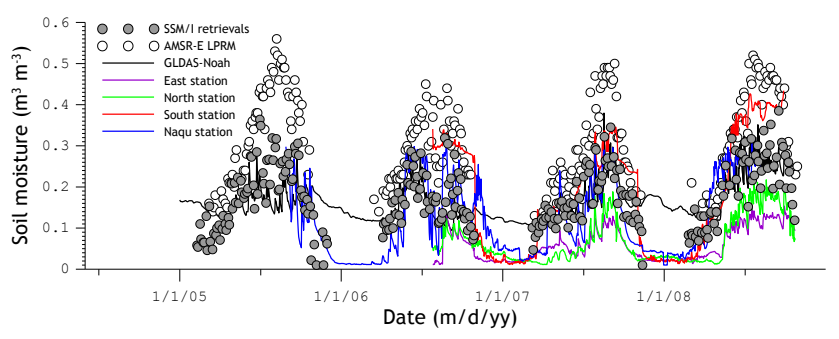

Fig. 6. Soil moisture measurements, SSM/I retrievals, AMSR-E LPRM estimates and GLDAS-Noah simulations of the $0.0-0.1 \mathrm{~m}$ soil layer at the Naqu network $\left(91.89^{\circ} \mathrm{E}, 31.36^{\circ} \mathrm{N}, \mathrm{WSG} 84\right)$ for the period 2005 to 2008 .

values up to $0.5(-)$ are observed predominantly in the eastern part of the Plateau, which decrease somewhat near the winter months. In general, much lower values $(<0.1)$ are retrieved over the Plateau's centre, whereas the optical depths found near the Yarlung valley are around 0.3 (-). This spatial optical depth distribution is comparable to monthly Normalised Difference Vegetation Index (NDVI) climatology recently reported in Zhong et al. (2010).

\subsection{Comparison with in situ measurements at validation site}

The consistency noted within the soil moisture and optical depth climatologies provides some confidence in the SSM/I products. A comparison with in situ measurements collected in the Naqu river basin is presented to further evaluate the accuracy of individual soil moisture retrievals. The Naqu soil moisture network consisted during the study period of five stations of which four operational. Figure 6 presents time series of these in situ measurements, SSM/I retrievals and GLDAS-Noah simulations of the $0.0-0.1 \mathrm{~m}$ layer for the period 2005 to 2008. Additionally, LPRM soil moisture estimates based on AMSR-E C-band $T_{\mathrm{B}}$ observed at night are shown. The measurements taken from a $2.5 \mathrm{~cm}$ depth are shown for the three grassland sites (north, east and Naqu) and from a $7.5 \mathrm{~cm}$ depth for the wetland site (south) because the shallowest probe at this site did not function.

In general, the plot shows that the temporal dynamics of the SSM/I retrievals, AMSR-E LPRM product and GLDASNoah simulations are in agreement with each other and the measurements. The AMSR-E soil moisture typically overestimates the in-situ measurements, which is well-known for LPRM product and has previously been reported in, for instance, Wagner et al. (2007) and Draper et al. (2009). On the other hand, a larger spread is noted among the SSM/I data points in comparison to the AMSR-E LPRM soil moisture. This can be explained by the fact that the low frequency AMSR-E observations are more sensitive to soil moisture than the SSM/I observations. Nevertheless, the SSM/I retrievals agree fairly well with the both AMSR-E LPRM and

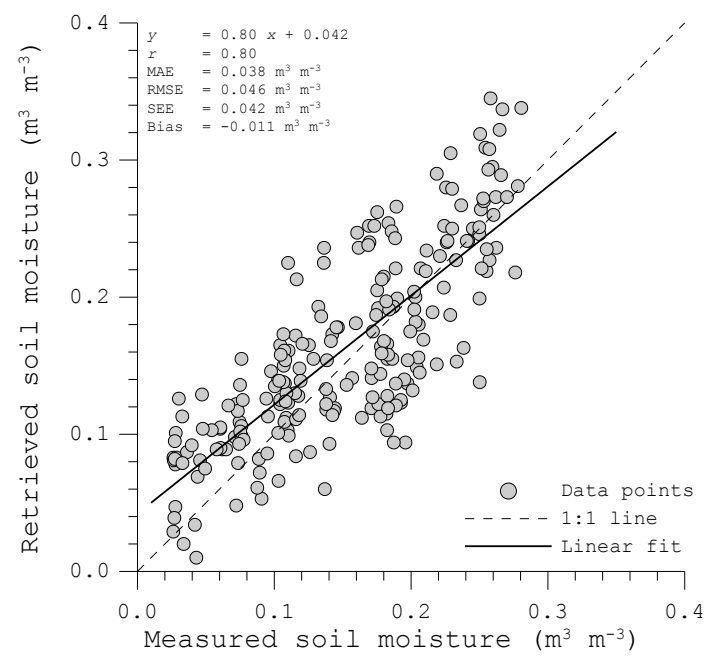

Fig. 7. SSM/I retrievals plotted against the arithmetic mean of soil moisture measurements collected at four stations within a single footprint (225 matchups).

in situ soil moisture based on which we justify its use for evaluation of the long-term trends over the Tibetan Plateau.

Particularly the SSM/I retrievals match the timing of the measured soil moisture increase/decrease associated with the onset/decline of the monsoon. The SSM/I soil moisture also captures the persistent dry (e.g. summer 2006, spring 2007) and wet (e.g. summer 2007) episodes noted via the in situ measurements. The correlation of SSM/I retrievals with individual soil moisture measurements is, however, less well-defined. This is somewhat expected because of the large spatial soil moisture variability observed in nature (e.g. Famiglietti et al., 1999). A time series measured at a specific site is, therefore, unlikely to fully represent the dynamics of coarse resolution observations. In fact, coarse resolution soil moisture retrievals are often validated against measurements from numerous sites collected during intensive field campaigns (Jackson, 1997; Wen et al., 2005; Jackson et al., 2010).

As an approximation of this widely accepted validation approach, the individual soil moisture retrievals are plotted in Fig. 7 against the arithmetic mean of the measurements from the four stations that are all located with the same SSM/I pixel. Some additional statistics are provided to quantify the relationships observed between retrieved and measured soil moisture, such as Pearson product-moment correlation coefficient ( $r$ ), Root Mean Squared Error (RMSE), Standard Error of Estimate (SEE), and bias calculated as,

$$
\begin{aligned}
r= & \sum_{i=1}^{n}\left(\theta_{\mathrm{sat}}^{i}-\bar{\theta}_{\mathrm{sat}}\right)\left(\theta_{\mathrm{grd}}^{i}-\bar{\theta}_{\mathrm{grd}}\right) \\
& / \sqrt{\sum_{i=1}^{n}\left(\theta_{\mathrm{sat}}^{i}-\bar{\theta}_{\mathrm{sat}}\right)^{2} \sum_{i=1}^{n}\left(\theta_{\mathrm{grd}}^{i}-\bar{\theta}_{\mathrm{grd}}\right)^{2}}
\end{aligned}
$$




$$
\begin{aligned}
\text { RMSE } & =\sqrt{\frac{1}{n} \sum_{i=1}^{n}\left(\theta_{\mathrm{sat}}^{i}-\theta_{\mathrm{grd}}^{i}\right)^{2}} \\
\mathrm{SEE} & =\sqrt{\frac{1}{n-2} \sum_{i=1}^{n}\left(\hat{\theta}_{\mathrm{sat}}^{i}-\theta_{\mathrm{grd}}^{i}\right)^{2}} \\
\operatorname{Bias} & =\frac{1}{n} \sum_{n=1}^{N}\left(\theta_{\mathrm{sat}}^{i}-\theta_{\mathrm{grd}}^{i}\right)
\end{aligned}
$$

where, $\theta$ is the soil moisture content $\left(\mathrm{m}^{3} \mathrm{~m}^{-3}\right)$, subscripts sat and grd indicate that the variable represents respectively the SSM/I and in-situ soil moisture, the bar $\left(^{-}\right)$stands for the mean of the dataset and $\hat{\theta}_{\text {sat }}^{i}$ is the estimate of the SSM/I retrievals obtained by applying a linear regression equation fitted through the SSM/I - in-situ soil moisture pairs.

The $r$ defined above (Eq. 7a) is calculated for the entire dataset and is, thus, influenced by the seasonality. To assess the ability of SSM/I retrieval in capturing day-to-day variability, the anomaly correlation coefficient $\left(r_{\text {ano }}\right)$ is computed as well. This is done by calculating normalised (or standardised) anomalies $(N)$ of both the daily SSM/I retrievals and in-situ measurements over a five-week gliding window as

$N_{\text {daily }}=\frac{\theta_{\text {daily }}-\mu_{5 \mathrm{wk}}}{\sigma_{5 \mathrm{wk}}}$

where, $N_{\text {daily }}$ is the normalised anomaly computed from daily values, $\theta_{\text {daily }}$ is the daily soil moisture either measured in-situ or retrieved from SSM/I $T_{\mathrm{B}}$ 's $\left(\mathrm{m}^{3} \mathrm{~m}^{-3}\right), \mu_{5 \mathrm{wk}}$ is the five-week mean soil moisture $\left(\mathrm{m}^{3} \mathrm{~m}^{-3}\right)$ and $\sigma_{5 \mathrm{wk}}$ is the five-week standard deviation $\left(\mathrm{m}^{3} \mathrm{~m}^{-3}\right)$. Then, the $r_{\text {ano }}$ is determined as $r$ computed from the two anomaly datasets according to Albergel et al. (2013).

Although insufficient spatially distributed measurements are available for a thorough validation, the SEE obtained with our limited set is better than the values reported in previous SSM/I studies (e.g. Jackson, 1997; Jackson et al., 2002; Wen et al., 2005). This can be argued for as these authors investigated the soil moisture retrieval from SSM/I observations over the more densely vegetated regions (Oklahoma and Iowa) in the United States. Further, with a $r_{\text {ano }}$ of 0.39 is the performance of SSM/I retrievals over the Naqu sites also comparable to that of the soil moisture products evaluated in Albergel et al. (2013). Moreover, the RMSE of $0.046 \mathrm{~m}^{3} \mathrm{~m}^{-3}$ approaches the value that is required of products proposed as a part of current and future soil moisture missions (e.g. Kerr et al., 2001; Entekhabi et al., 2010). As such, the agreement found between the retrieved and measured soil moisture at the test site is in line with the "state of the art".

\subsection{Plateau scale verification}

The presented comparison with the Naqu measurements validates the SSM/I soil moisture for a single location, while the land surface conditions affecting the retrieval accuracy

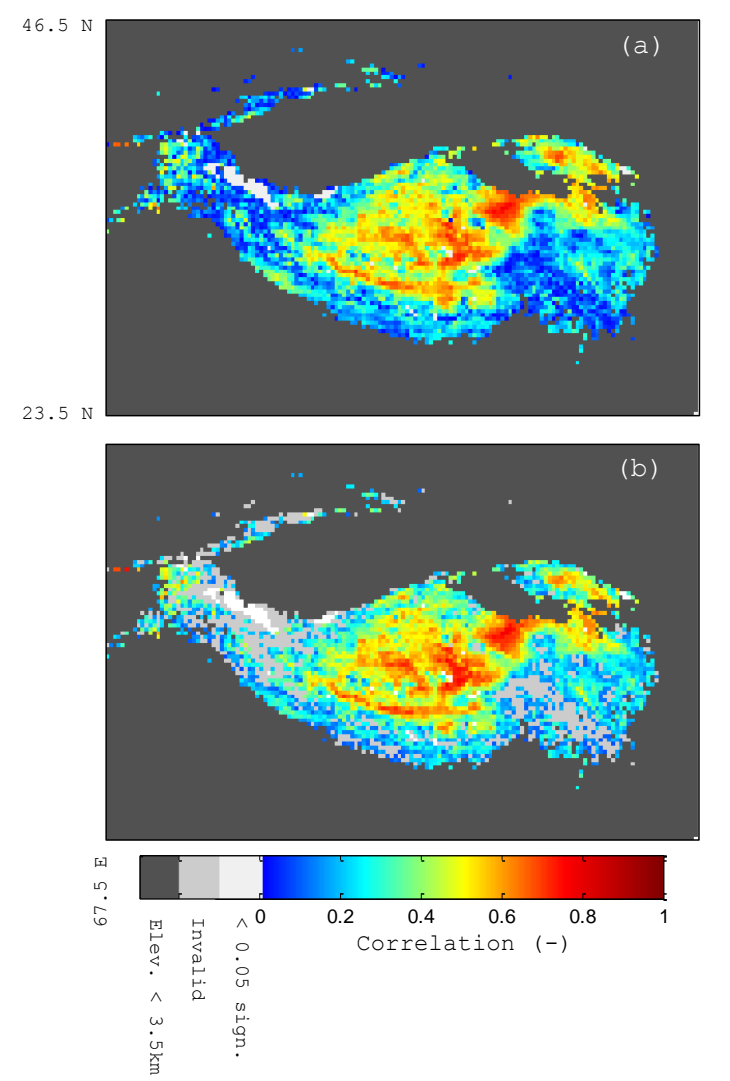

Fig. 8. Pearson product-moment (a) and Spearman rank (b) correlation coefficients calculation between SSM/I retrieved and GLDASNoah simulated soil moisture. Only the Spearman correlation coefficients determined at a significance level better than 0.05 are shown.

vary across the plateau. Unfortunately, the Tibetan Plateau Soil Moisture Observatory (Su et al., 2011) was not yet fully developed during the selected SSM/I study period. For a plateau-scale verification, we choose to utilise $0.25^{\circ}$ spatial resolution three hourly soil moisture simulations performed by the Noah LSM with the GLDAS. The comparison between Noah simulated and SSM/I retrieved soil moisture is made for the period 2005 to 2008 . The result of the comparison between the SSM/I and GLDAS-Noah soil moisture is summarised in Fig. 8. Figure 8 presents the $r$ and Spearman rank correlation coefficients $(\rho)$. For the latter, only values are shown that are determined at a significance level larger than 0.05 . The product-moment and rank correlation coefficients are chosen for the evaluation to reduce the effect of the inherent bias between the SSM/I and GLDAS-Noah climatology on the comparison.

Figure 8a shows that for large areas situated primarily in the Plateau's centre more than $50 \%$ of the computed Pearson product-moment correlation coefficients may reach values higher than 0.60. Lower $r$ values are noted in regions with mountain peaks and at the periphery of the Plateau 
where the land cover consists either of mountain peaks or forests. Across the Plateau's centre, Spearman rank correlation coefficients with similar magnitudes are obtained, which indicates that the relationship between the SSM/I and GLDAS-Noah soil moisture is linear. Further, more than $80 \%$ of the $\rho$ values are determined at a significance level larger than 0.05 . The agreement found between the retrievals and the independent GLDAS-Noah dataset indicates that the $\mathrm{SSM} / \mathrm{I}$ data product is skilful specifically given the fact that the timing of rain events is subject to large uncertainties (Reichle et al., 2004).

\section{Analysis of observed trends}

\subsection{Method}

After assessing the SSM/I retrievals using in situ measurements and GLDAS-Noah simulations, we present in this section an analysis of the trends within the SSM/I soil moisture products available from July 1987 to December 2008. This analysis is performed on a monthly basis and for the warm season (May to October) as a whole. Daily soil moisture estimates are averaged to monthly values when at least five valid retrievals are available and the monthlies are averaged to seasonal values when for at least five of the six months a valid value is available. Normalised (or standardised) anomalies are computed from the monthly and warm season mean soil moisture to allow comparisons of different months and across the Plateau. This would otherwise not be possible because of the strong seasonal dynamics. The monthly $\left(N_{\text {month }}\right)$ and warm season $\left(N_{\text {season }}\right)$ normalised anomaly is here defined as

$$
\begin{gathered}
N_{\text {month }}=\frac{\theta_{\text {month }}-\mu_{\text {month }}}{\sigma_{\text {month }}} \\
N_{\text {season }}=\frac{\theta_{\text {season }}-\mu_{\text {season }}}{\sigma_{\text {season }}}
\end{gathered}
$$

where, $\theta_{\text {month }}$ and $\theta_{\text {season }}$ stand for respectively the monthly or warm season mean soil moisture computed from retrievals of an individual year $\left(\mathrm{m}^{3} \mathrm{~m}^{-3}\right), \mu_{\text {month }}$ and $\mu_{\text {season }}$ are respectively the multi-year mean of the monthly or warm season soil moisture $\left(\mathrm{m}^{3} \mathrm{~m}^{-3}\right), \sigma_{\text {month }}$ and $\sigma_{\text {season }}$ stand for respectively the multi-year standard deviation of the monthly or warm season soil moisture $\left(\mathrm{m}^{3} \mathrm{~m}^{-3}\right)$. The $\mu$ and $\sigma$ are, thus, computed using the entire 1987-2008 SSM/I dataset for either individual months or the complete warm season.

The relationship of the $N$ ( $N_{\text {month }}$ as well as $\left.N_{\text {season }}\right)$ with time is evaluated by fitting the following linear function for each SSM/I pixel through the data points

$\hat{N}=a \cdot t+b$

where, $\hat{N}$ is the estimated normalised soil moisture anomaly $(-), t$ is time (year), $a$ and $b$ are respectively the slope and

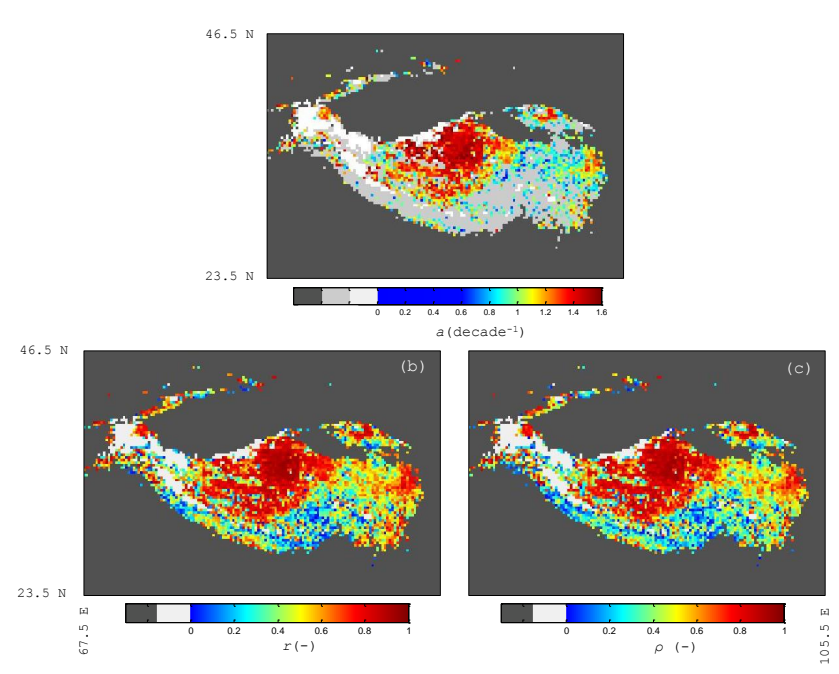

Fig. 9. The relationship of the warm season $N\left(N_{\text {season }}\right)$ with time; (a) shows slope of a linear function fitted through the data points (a), (b) and (c) show the respectively the Pearson and Spearman correlation coefficients between the $N_{\text {season }}$ and time. Invalid results are displayed as white, $N_{\text {season }}$ trends $(a)$ determined with a significance level less than 0.05 are masked light-grey.

intercept of the linear function (year ${ }^{-1}$ and - , respectively). The slope, $a$, of the linear function quantifies the normalised soil moisture anomaly trend. In addition, the $r$ and $\rho$ are calculated to further quantify the relationship between the $N$ and time. Pixels are only used for the analysis when the monthly or warm season values are available for at least fifteen (non-consecutive) of the in total twenty-two years.

\subsection{Warm season and monthly trends}

Figure 9 shows for the Tibetan Plateau the results of relationships between the $N_{\text {season }}$ with time obtained by fitting a linear function through the data points. Figure 9a displays the slope ( $a$ ) as measure of the $N_{\text {season }}$ trend per decade, and Fig. $9 \mathrm{~b}$ and c present respectively the $r$ and $\rho$ computed between $N_{\text {season }}$ and time. Note that the values for $a$ are only shown when both $r$ and $\rho$ are determined with a significance larger than 0.05. Similarly, Fig. 10 provides maps of $a, r$ and $\rho$ for the Plateau derived for each of the months from May to October. Further, Fig. 11 presents for reference purposes time series of monthly $\mathrm{H}$ polarized $19 \mathrm{GHz} T_{\mathrm{B}}$ and the monthly difference of the $\mathrm{V}$ and $\mathrm{H}$ polarized $19 \mathrm{GHz} T_{\mathrm{B}}$ measured by the SSM/I over the area with largest significant soil moisture trend.

Analysis of warm season anomalies reveals a very distinctive spatial distribution. In Fig. 9, $r$ and $\rho$ values larger than 0.7 dominate the centre of the Plateau where also the matchup of SSM/I and GLDAS-Noah soil moisture is favourable. Associated with these high correlations are $N_{\text {season }}$ trends of 0.8 to $1.6 \mathrm{decade}^{-1}$. This means that in some of these areas the SSM/I soil moisture estimates have 


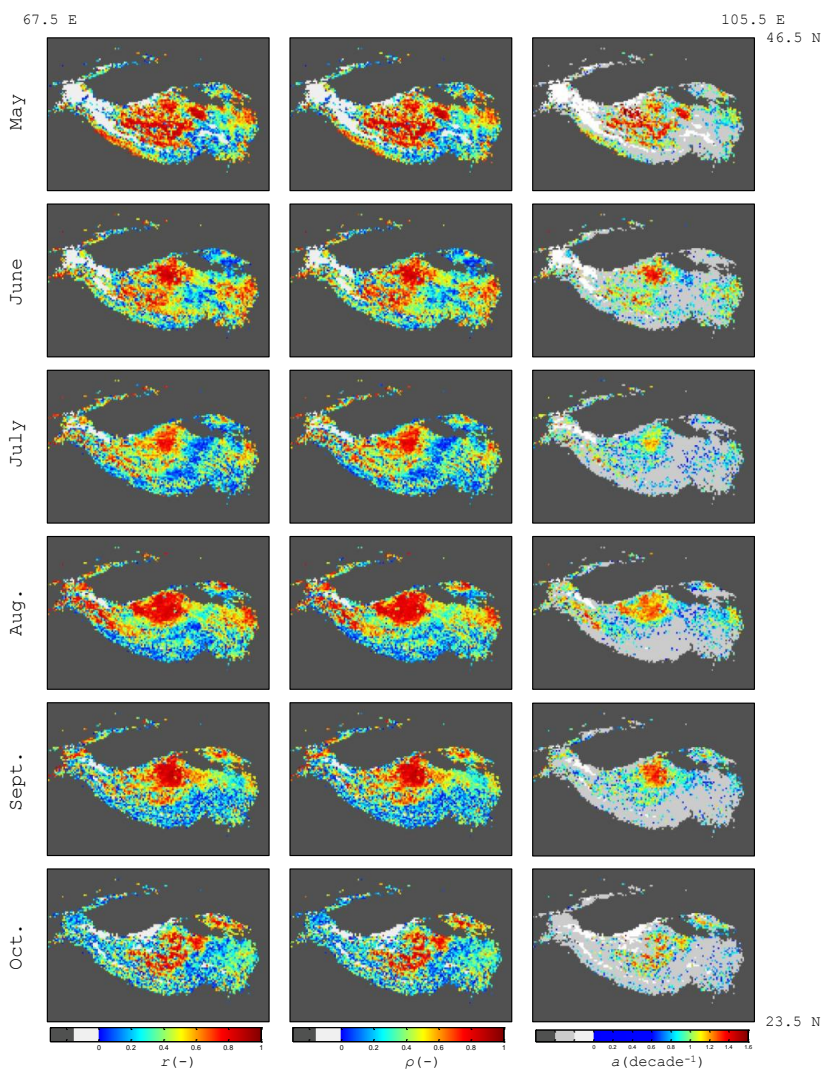

Fig. 10. The relationship of the monthly $N\left(N_{\text {month }}\right)$ with time for May to October; left and center panels show the Pearson and Spearman correlation coefficients, the right panels show the slope of a linear function fitted through the data points. Invalid results are displayed as white, $N_{\text {month }}$ trends ( $a$ ) determined with a significance level less than 0.05 are masked light-grey.

increased on average by $60 \%$ more than the standard deviation per decade. It should, however, be noted that the soil moisture climatology in this region (see Fig. 4) is at a very low level. A similar absolute change results, thus, in a larger $N_{\text {season }}$ change as compared to wet regions.

Along the southern periphery from west to east lower values are obtained for both $r$ and $\rho$. In many cases the correlation coefficients do not pass the selected significance test and, therefore, the $a$ values are masked. It is very difficult to detect reliably a systematic $N_{\text {season }}$ trend from the SSM/I soil moisture estimates in this region. This could be because little change has occurred, but also uncertainties associated with the retrieval form an explanation. For instance, the vegetation optical depth can be substantial in this region, which increases the uncertainty of soil moisture retrievals. Further, the significant relief and mountain ranges to the south contribute also to the uncertainty, which is reflected in the disagreement between SSM/I and GLDAS-Noah soil moisture.

Albeit the uncertainties associated with detecting a trend along the southern periphery, a significant positive $N_{\text {season }}$ trend or wetting of the soil is noted across the Plateau's cen- tre. This observation is in line with the findings of previous studies that have investigated hydrological changes on the Tibetan Plateau (Yang et al., 2011a). For instance, the retreat of permafrost caused by a surface temperature rise could be one of the factors contributing to the wetting (e.g. Li et al., 2012). Further, the decrease in potential evapotranspiration $\left(\mathrm{ET}_{\mathrm{pot}}\right)$ due to either wind stilling or solar dimming (e.g. Yang et al., 2012; Zhang et al., 2009) can cause higher soil moisture contents and also the precipitation increase (e.g. Liu et al., 2009; Lei et al., 2013) explains inevitably part of the land surface wetting. A detailed quantification of each component and its contribution to the total trend is, however, beyond the scope of this study.

The maps of $a, r$ and $\rho$ (see Fig. 10) obtained by fitting linear functions through data points of $N_{\text {month }}$ versus time display a similar spatial distribution as the warm season results. Significant positive $N_{\text {month }}$ trends up to $1.6 \mathrm{decade}^{-1}$ are noted in the centre of the Plateau, whereas it is difficult to detect a significant trend within the SSM/I retrieved soil moisture along the southern periphery and further to the east. Note that the similarity between the $r$ and $\rho$ maps observed for each month is an indication for the linearity of the $N$ relationship with time.

In May, the largest significant $N_{\text {month }}$ trends are observed in terms of both extent and magnitude. The magnitude as well as extent of the area with $N_{\text {month }}$ trends declines towards July and, most notably, the magnitude increases again in August/September. Further towards the end of the monsoon, in October, the areas with a significant $N_{\text {month }}$ trend diminish and disperse across the Plateau's centre.

The seasonal pattern of observed $N_{\text {month }}$ trends can be argued for based on results reported in previous investigations. For instance, Salama et al. (2012) noted that the warming of the Plateau during the past three decades is largest in April/May and diminishes from October. This implicates that frozen soil water thaws earlier, which is an explanation for the higher moisture levels observed at the onset of the rain season. The contribution of thawing soil water decreases towards the summer when the total heat source is largest (Yang et al., 2011b), which can cause the smaller $N_{\text {month }}$ trends observed for June and specifically July.

The larger $N_{\text {month }}$ trends for August/September noted in the north-central part are more difficult to explain based on literature reports because most previous investigations relied strongly on in situ measurements for detecting trends in the hydrological cycle. Unfortunately, density of ground station operated by the Chinese Meteorological Administration (CMA) is low in this part of the Tibetan Plateau, which at the same time highlights the value of earth observations for monitoring land processes. Recent investigations, however, do report on a precipitation increase (Liu et al., 2009; Lei et al., 2013) and an $\mathrm{ET}_{\text {pot }}$ decrease (Zhang et al., 2009; Yang et al., 2012). Both can contribute to the observed land surface wetting. The explanation for the wetting in specifically the north-central part of the Plateau should probably be found in 


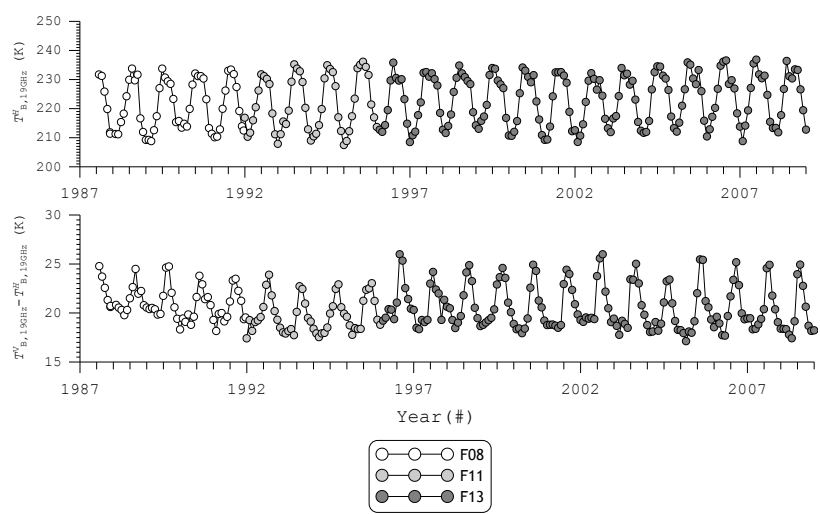

Fig. 11. Series of monthly $\mathrm{H}$ polarized $19 \mathrm{GHz} T_{\mathrm{B}}$ (upper panel) and the monthly difference of the $\mathrm{V}$ and $\mathrm{H}$ polarized $19 \mathrm{GHz} T_{\mathrm{B}}$ (lower panel) measured by the F08, F11 and F13 SSM/I satellites at $34.75^{\circ}$ latitude and $88.00^{\circ}$ longitude (WGS84).

the complex atmospheric circulations on the Plateau and the interactions with the surroundings (Zhang et al., 2009; Chen et al., 2013). Such investigation extends, however, beyond the scope of the present study.

\subsection{Dependence on elevation}

Recently, Qin et al. (2009) and Salama et al. (2012) showed using satellite observations that the warming rate on the Tibetan Plateau is correlated to the elevation. Previously, Giorgi et al. (1997) had demonstrated via regional climate model simulations that also various components of the surface energy and water budgets are stronger influenced by global warming in high-elevation regions. A comparison of Figs. 9 and 10 with the GTOPO30 DEM (see Fig. 1) suggests also an elevation-dependency of the $N$ trend.

Figure 12 illustrates this further by showing the trends derived from the $N_{\text {season }}$ and $N_{\text {month }}$ versus the GTOPO30 elevations averaged per SSM/I pixel. The data points and error bars in the plots represent respectively the mean and standard deviation of $N$ trends available for a specific $100 \mathrm{~m}$ elevation bin. In the upper left corner of each plot the linear regression equation is shown of the $N$ trend as function of altitude.

The $N_{\text {season }}$ trend displays a clear positive relationship with the elevation. At heights of 3.5 up to $4.9 \mathrm{~km}$ the $N_{\text {season }}$ trends fluctuate around $1.05 \mathrm{decade}^{-1}$, in the $4.9-5.2 \mathrm{~km}$ range the wetting rate increases from 1.05 to 1.30 decade $^{-1}$ and decreases slightly to $1.25 \mathrm{decade}^{-1}$ for higher altitudes. Similar $N_{\text {month }}$ trend relationships with elevation are found for May and the months June, August and September to lesser extent. It should, however, be noted that the altitude and magnitude of the accelerated wetting rate both shift throughout the seasons. For instance, the $N_{\text {month }}$ trend increases at a height of $4.4 \mathrm{~km}$ from 0.85 to almost 1.13 decade $^{-1}$ in May, whereas the accelerated wetting rate is barely noticeable at $4.9 \mathrm{~km}$ in June. The critical elevation

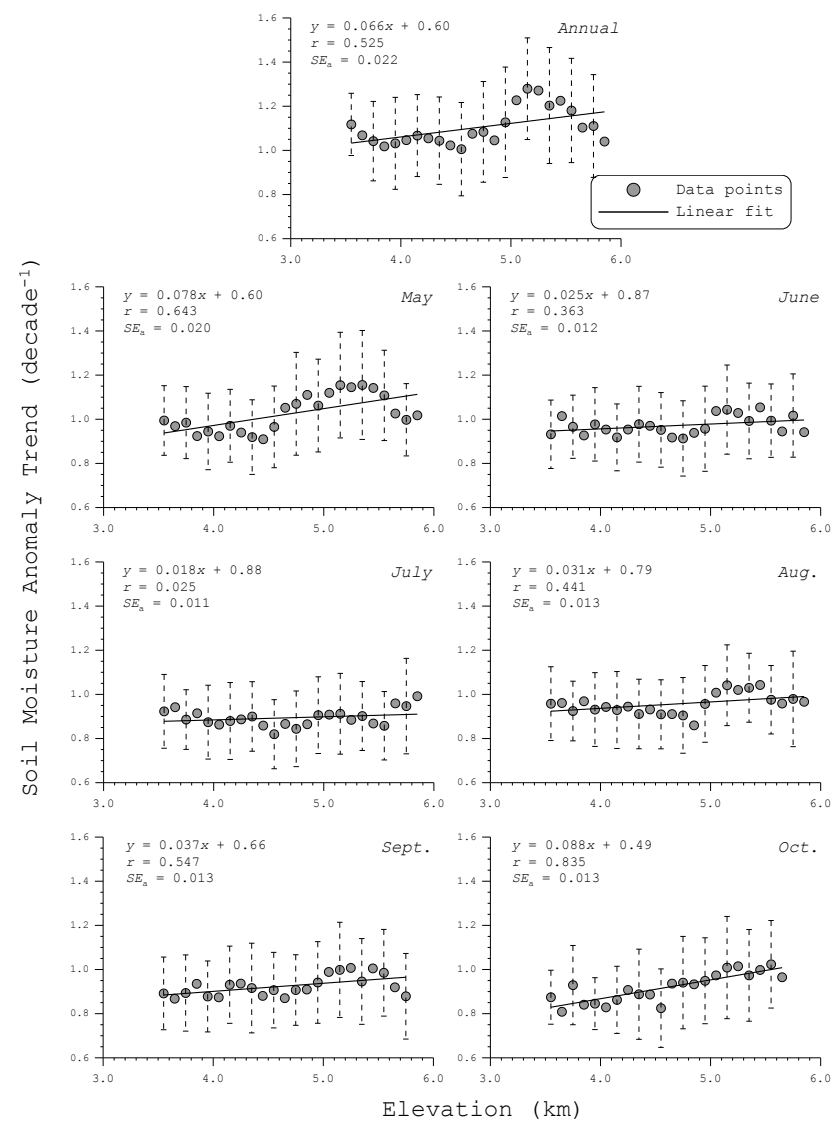

Fig. 12. $N$ trends determined on a warm season ( $N_{\text {season, }}$ upper panel) and monthly ( $N_{\text {month }}$, lower panels) basis plotted against elevation. The data points and errors bars represent respectively the mean and standard deviation of $N$ trends within a $100 \mathrm{~m}$ elevation bin. $\mathrm{SE}_{\mathrm{a}}$ stands for the standard error of the estimates parameter $a$ of the linear fit $y=a x+b$.

moves again downward to 4.8 and $4.6 \mathrm{~km}$ in August and September, respectively. Figure 12 further indicates that the warm season $N$ trends are larger than the monthly trends. This is caused by the inevitably larger interannual variability of the monthly soil moisture as compared to the warm season. The larger fluctuations in the monthly soil moisture reduce the calculated $N_{\text {month }}$ trends, which is also noted in Fig. 10.

The seasonality observed in the elevation-dependency of the $N_{\text {month }}$ trend suggests that the accelerated wetting observed at higher elevations is most probably associated with the retreat of regions subject to freeze-thaw transitions. Indeed, Li et al. (2012) recently reported on the retreat of permafrost regions across the Tibetan Plateau. The highelevation areas will inevitably be affected most during the onset and decline of warm season because in those periods most freeze-thaw transitions occur. Hence, clear positive relationships of the $N_{\text {month }}$ trends with elevation are noted for May and September/October, while an elevation-dependency 
of the $N_{\text {month }}$ trend is more difficult to identify for the months June, July and August. As such, this study provides observational evidence for the seasonality of the global warming impact on land surface hydrology of the Tibetan Plateau.

\section{Summary and remarks}

This paper discusses soil moisture retrievals of the Tibetan Plateau from brightness temperatures $\left(T_{\mathrm{B}}\right.$ 's) observed by the Special Sensor Microwave Imagers (SSM/I's) from July 1987 up to December 2008. For this study, the Fundamental Climate Data Record (FCDR) of the F08, F11 and F13 SSM/I satellites of the Precipitation Research Group of Colorado State University is utilised. The FCDR includes harmonized SSM/I datasets subjected to radiometric and geometric quality checks addressing issues, such as inter-sensor calibration, cross-track bias correction, orbital drift and navigational inaccuracies.

The algorithm developed for the retrieval of soil moisture is based on inversion of a radiative transfer model that simulates top-of-atmosphere $T_{\mathrm{B}}$ 's. Effects of the atmosphere are considered through an adapted version of the parameterization developed by Pellarin et al. (2006), for which the bias-corrected atmospheric forcings described in Sheffield et al. (2006) are selected as input. Land surface contributions are computed via the well known $\tau-\omega$ model. Within this setup, the algorithm utilises the vertically (V) polarized $37 \mathrm{GHz} T_{\mathrm{B}}$ to estimate the effective temperature. The dielectric constant and optical depth $(\tau)$ are both inverted from the horizontally $(\mathrm{H})$ and $\mathrm{V}$ polarized $19 \mathrm{GHz} T_{\mathrm{B}}$ 's via a least squares optimisation routine. Subsequently, the dielectric constant is transformed into soil moisture using Dobson et al.'s (1985) dielectric mixing model with soil texture maps as input.

Validation of SSM/I retrievals against in situ soil moisture measured at four stations within a single SSM/I pixel for a two-and-half year period (225 matchups) yields a Root Mean Squared Error of $0.046 \mathrm{~m}^{-3} \mathrm{~m}^{-3}$, respectively. These errors levels are better than results obtained in previous studies that made use of SSM/I observations and almost in agreement with the accuracy requirements of satellite missions specifically dedicated to soil moisture. On a Plateau-scale, the agreement found between the retrievals and the Noah simulations produced by the Global Land Data Assimilation System (GLDAS-Noah) further supports the reliability of the SSM/I soil moisture. The correlation coefficients found between SSM/I and GLDAS-Noah are larger than 0.6 for a large area situated in the central part of the Tibetan Plateau.

For the analysis of trends, normalised soil moisture anomalies $(N)$ are computed from the SSM/I soil moisture products available from July 1987 to December 2008 for warm season (May-October) and individual months of the warm season. The slope of linear regression functions fitted between $N$ and time is used to quantify the $N$ trend across the
Plateau. Pearson product-moment and Spearman rank correlation coefficients are further utilised as measure for the significance of the detected trend.

From the warm season $N$ significant positive trends of 0.8 to almost 1.6 decade $^{-1}$ are derived for the centre part of the Tibetan Plateau. Similar spatial distributions of $N$ trends are obtained on a monthly basis whereby the largest wetting is noted in May, which declines towards July and increases again in August/September to diminish at the end of the monsoon in October. The magnitude of trends is found to be correlated with the elevation for the warm season $N$ and the monthly $N$ computed for May, September and October. This suggests that the accelerated wetting observed at high elevations is associated with the retreat of region subject to freeze-thaw transitions.

In general, the severe wetting observed across the center of the Tibetan Plateau can be attributed to previously reported changes in hydro-meteorological processes associated with global warming, such as the retreat of permafrost, increase in precipitation and decline of potential evapotranspiration. Inevitably, the wetting affects changes in the complex atmospheric circulation over the Tibetan Plateau through water and energy exchanges at the land-atmosphere interface, which also contributes for some extent to the observed weakening of the East Asian summer Monsoon. Additional investigations are, however, needed to evaluate in more detail how the Tibetan land surface interacts with the atmosphere and how these interactions affect the atmospheric circulation at a larger scale.

Acknowledgements. The authors would like to thank Dr. Wesley Berg of the Precipitation Research Group from Colorado State University for providing the Fundamental Climate Data Record (FCDR) of the SSM/I data. Dr. Catherine Prigent of Observatoire de Paris of the CNRS is acknowledged for providing their global decadal emissivity dataset. The GLDAS-Noah data used in this study were acquired as part of the mission of NASA's Earth Science Division and archived and distributed by the Goddard Earth Sciences (GES) Data and Information Services Center (DISC). Further, this study was supported in part by the Chinese Academy of Sciences Fellowship for Young International Scientists (Grant No. 2012Y1ZA0013) and the FP7 CEOP-AEGIS project funded by the European Commission through the FP7 programme.

Edited by: N. Romano 


\section{References}

Albergel, C., Dorigo, W., Reichle, R. H., Balsomo, G., De Rosnay, P., Munoz-Sabater, J., Isaksen, L., De Jeu, and Wagner, W.: Skill and global trend analysis of soil moisture from reanalysis and microwave remote sensing, J. Hydrometeorol., 14, 1259-1277, 2013.

Berg, W., Sapiano, M. R. P., Horsman, J., and Kummerow, C.: Improved geolocation and earth incidence angle information for a fundamental climate data record of SSM/I sensors, IEEE Trans. Geosci. Remote Sens., 51, 1504-1513, 2013.

Chen, S., Huang, J., Zhao, C., Qian, Y., Leung, L. R., and Yang, B.: Modeling the transport and radiative forcing of Taklimakan dust over the Tibetan Plateau: A case study in the summer of 2006, J. Geophys. Res.-Atmos., 118, 797-812, doi:10.1002/jgrd.50122, 2013.

Choudhury, B. J.: Reflectivities of Selected Land-Surface Types at 19 and $37 \mathrm{Ghz}$ from SSM/I Observations, Remote Sens. Environ., 46, 1-17, 1993.

Cosh, M. H., Jackson, T. J., Bindlish, R., Famiglietti, J. S., and Ryu, D.: Calibration of an impedance probe for estimation of surface soil water content over large regions, J. Hydrol., 311, 49-58, 2005.

De Jeu, R. A. M. and Owe, M.: Further validation of a new methodology for surface moisture and vegetation optical depth retrieval, Int. J. Remote Sens., 24, 4559-4578, 2003.

Dobson, M. C., Ulaby, F. T., Hallikainen, M. T., and El-Rayes, M. A.: Microwave dielectic behavior of wet soil - Part II: Dielectric mixing models, IEEE Trans. Geosci. Remote Sens., GE-23, 3546, 1985.

Draper, C. S., Walker, J. P., Steinle, P. J., de Jeu, R. A. M., and Holmes, T. R. H.: An evaluation of AMSR-E derived soil moisture over Australia, Remote Sens. Environ., 113, 703-710, 2009.

Drusch, M., Wood, E. F., and Jackson, T. J.: Vegetative and atmospheric corrections for the soil moisture retrieval from passive microwave remote sensing data: Results from the Southern Great Plains Hydrology Experiment 1997, J. Hydrometeorol., 2, 181192, 2001.

Dubois, P. C., Van Zyl, J., and Engman, T.: Measuring SoilMoisture with Imaging Radars, IEEE Trans. Geosci. Remote Sens., 33, 915-926, 1995.

Entekhabi, D., Njoku, E. G., O’Neill, P. E., Kellogg, K. H., Crow, W. T., Edelstein, W. N., Entin, J. K., Goodman, S. D., Jackson, T. J., Johnson, J., Kimball, J., Piepmeier, J. R., Koster, R. D., Martin, N., McDonald, K. C., Moghaddam, M., Moran, S., Reichle, R., Shi, J.-C., Spencer, M. W., Thurman, S. W., Leung Tsang, and Van Zyl, J.: The Soil Moisture Active Passive (SMAP) mission, Proc. IEEE, 98, 704-716, 2010.

Famiglietti, J. S., Devereaux, J. A., Laymon, C. A., Tsegaye, T., Houser, P. R., Jackson, T. J., Graham, S. T., Rodell, M., and van Oevelen, P. J.: Ground-based investigation of soil moisture variability within remote sensing footprints during the Southern Great Plains 1997 (SGP97) Hydrology Experiment, Water Resour. Res., 35, 1839-1851, 1999.

Gao, H., Wood, E. F., Jackson, T. J., Drusch, M., and Bindlish, R.: Using TRMM/TMI to retrieve surface soil moisture over the southern United States from 1998 to 2002, J. Hydrometeorol., 7, 23-38, 2006.
Giorgi, F., Hurrell, J. W., Marinucci, M. R., and Beniston, M.: Elevation dependency of the surface climate change signal: A model study, J. Climate, 10, 288-296, 1997.

Hansen, M., DeFries, R., Townshend, J. R. G., and Sohlberg, R.: UMD Global Land Cover Classification, 1 Kilometer, 1.0, Department of Geography, University of Maryland, College Park, Maryland, 1981-1994, 1998.

Hollinger, J. P., Peirce, J. L., and Poe, G. A.: SSM/I Instrument Evaluation, IEEE Trans. Geosci. Remote Sens., 28, 781-790, 1990.

Holmes, T. R. H., De Jeu, R. A. M., Owe, M., and Dolman, A. J.: Land surface temperature from $\mathrm{Ka}$ band $(37 \mathrm{GHz})$ passive microwave observations, J. Geophys. Res.-Atmos., 114, D04113, doi:10.1029/2008jd010257, 2009.

Jackson, T. J.: Soil moisture estimation using special satellite microwave/imager satellite data over a grassland region, Water Resour. Res., 33, 1475-1484, 1997.

Jackson, T. J. and Hsu, A. Y.: Soil moisture and TRMM microwave imager relationships in the Southern Great Plains 1999 (SGP99) Experiment, IEEE Trans. Geosci. Remote Sens., 39, 1632-1642, 2001.

Jackson, T. J. and Schmugge, T. J.: Passive Microwave RemoteSensing System for Soil-Moisture - Some Supporting Research, IEEE Trans. Geosci. Remote Sens., 27, 225-235, 1989.

Jackson, T. J., O'Neill, P. E., and Swift, C. T.: Passive microwave observation of diurnal surface soil moisture, IEEE Trans. Geosci. Remote Sens., 35, 1210-1222, 1997.

Jackson, T. J., Le Vine, D. M., Hsu, A. Y., Oldak, A., Starks, P. J., Swift, C. T., Isham, J. D., and Haken, M.: Soil moisture mapping at regional scales using microwave radiometry: The Southern Great Plains Hydrology Experiment, IEEE Trans. Geosci. Remote Sens., 37, 2136-2151, 1999.

Jackson, T. J., Hsu, A. Y., and O’Neill, P. E.: Surface soil moisture retrieval and mapping using high-frequency microwave satellite observations in the Southern Great Plains, J. Hydrometeorol., 3, 688-699, 2002.

Jackson, T. J., Cosh, M. H., Bindlish, R., Starks, P. J., Bosch, D. D., Seyfried, M., Goodrich, D. C., Moran, M. S., and Du, J.: Validation of Advanced Microwave Scanning Radiometer soil moisture product, IEEE Trans. Geosci. Remote Sens., 48, 4256-4272, 2010.

Joseph, A. T., Van der Velde, R., O’Neill, P. E., Choudhury, B. J., Lang, R. H., Kim, E. J., and Gish, T.: L Band brightness temperature observations over a corn canopy during the entire growth cycle, Sensors, 10, 6980-7001, 2010.

Kerr, Y. H. and Njoku, E. G.: A Semiempirical Model for Interpreting Microwave Emission from Semiarid Land Surfaces as Seen from Space, IEEE Trans. Geosci. Remote Sens., 28, 384-393, 1990.

Kerr, Y. H., Waldteufel, P., Wigneron, J. P., Martinuzzi, J. M., Font, J., and Berger, M.: Soil moisture retrieval from space: The Soil Moisture and Ocean Salinity (SMOS) mission, IEEE Trans. Geosci. Remote Sens., 39, 1729-1735, 2001. 
Koster, R. D., Dirmeyer, P. A., Guo, Z., Bonan, G., Chan, E., Cox, P., Gordon, C. T., Kanae, S., Kowalczyk, E., Lawrence, D., Liu, P., Lu, C.-H., Malyshev, S., McAvaney, B., Mitchell, K., Mocko, D., Oki, T., Oleson, K., Pitman, A., Sud, Y. C., Taylor, C. M., Verseghy, D., Vasic, R., Xue, Y., and Yamada, T.: Regions of strong coupling between soil moisture and precipitation, Science, 305, 1138-1140, 2004.

Lau, K. M., Kim, M. K., and Kim, K. M.: Asian summer monsoon anomalies induced by aerosol direct forcing: the role of the Tibetan Plateau, Clim. Dynam., 26, 855-864, 2006.

Lei, Y., Yao, T., Bird, B. W., Yang, K., Zhai, J., and Sheng, Y.: Coherent lake growth on the central Tibetan Plateau since the 1970s: Characterization and attribution, J. Hydrol., 483, 61-67, 2013.

Li, X., Jin, R., Pan, X., Zhang, T., and Guo, J.: Changes in the nearsurface soil freeze-thaw cycle on the Qinghai-Tibetan Plateau, Int. J. Appl. Earth Obs., 17, 33-42, 2012.

Liu, J. S., Wang, S. Y., Yu, S. M., Yang, D. Q., and Zhang, L.: Climate warming and growth of high-elevation inland lakes on the Tibetan Plateau, Global Planet. Change, 67, 209-217, 2009.

Ma, Y. M., Zhong, L., Su, Z. B., Ishikawa, H., Menenti, M., and Koike, T.: Determination of regional distributions and seasonal variations of land surface heat fluxes from Landsat7 Enhanced Thematic Mapper data over the central Tibetan Plateau area, J. Geophys. Res.-Atmos., 111, D10305, doi:10.1029/2005jd006742, 2006.

Mo, T., Choudhury, B. J., Schmugge, T. J., Wang, J. R., and Jackson, T. J.: A Model for Microwave Emission from VegetationCovered Fields, J. Geophys. Res.-Ocean. Atmos., 87, 12291237, 1982.

Moghaddam, M. and SMAP soil moisture alogirthms team: SMAP Level-2 soil moisture Cal/Val requirements, 2nd SMAP Cal/Val workshop, Oxnard CA, USA, 2-5 May, 2011, available at: http://www.hydrology-and-earth-system-sciences.net/ Copernicus_Publications_Reference_Types.pdf, 2011.

Njoku, E. G. and Li, L.: Retrieval of land surface parameters using passive microwave measurements at 6-18 GHz, IEEE Trans. Geosci. Remote Sens., 37, 79-93, 1999.

Njoku, E. G., Jackson, T. J., Lakshmi, V., Chan, T. K., and Nghiem, S. V.: Soil moisture retrieval from AMSR-E, IEEE Trans. Geosci. Remote Sens., 41, 215-229, 2003.

Owe, M., De Jeu, R., and Holmes, T.: Multisensor historical climatology of satellite-derived global land surface soil moisture, J. Geophys. Res., 113, F01002, doi:10.1029/2007JF000769, 2008.

Pellarin, T., Wigneron, J.-P., Calvet, J.-C., Berger, M., Douville, H., Ferrazoli, P., Kerr, Y. H., Lopez-Baeza, E., Pulliainen, J., Simmonds, L. P., and Waldteufel, P.: Two-year global simulation of L-band brightness temperatures over land, IEEE Trans. Geosci. Remote Sens., 41, 2135-2139, 2003.

Pellarin, T., Kerr, Y. H., and Wigneron, J.-P.: Global simulation of brightness temperatures at 6.6 and $10.7 \mathrm{GHz}$ over land based on SMMR dataset analysis, IEEE Trans. Geosci. Remote Sens., 44, 2492-2504, 2006.

Prigent, C., Aires, F., and Rossow, W. B.: Land surface microwave emissivities over the globe for a decade, Bull. Am. Meteorol. Soc., 87, 1573-1584, 2006.

Qin, J., Yang, K., Liang, S., and Guo Z.: The altitudinal dependence of recent rapid warming over theTibetan Plateau, Clim. Change, 97, 321-327, 2009.
Reichle, R. H., Koster, R. D., Dong, J., and Berg, A. A.: Global soil moisture from satellite observations, land surface models, and ground data: Implication for data assimilation, J. Hyrometeorol, 5, 430-442, 2004.

Reynolds, C. A., Jackson, T. J., and Rawls, W. J.: Estimating soil water-holding capacities by linking the Food and Agriculture Organization soil map of the world with global pedon databases and continuous pedotransfer functions, Water Resour. Res., 36, 3653-3662, 2000.

Rodell, M., Houser, P. R., Jambor, U., Gottschalck, J., Mitchell, K., Meng, C.-J., Arsenault, K., Cosgrove, B., Radakovich, J., Bosilovich, M., Entin, J. K., Walker, J. P., Lohmann, D., and Toll, D.. The Global Land Data Assimilation System, Bull. Am. Meteorol. Soc., 85, 381-394, 2004.

Salama, M. S., Van der Velde, R., Zhong, L., Ma, Y. M., Ofwono, M., and Su, Z.: Decadal variations of land surface temperature anomalies observed over the Tibetan Plateau by the Special Sensor Microwave Imager (SSM/I) from 1987 to 2008, Clim. Change, 114, 769-781, 2012.

Semunegus, H., Berg, W., Bates, J. J., Knapp, K. R., and Kummerow, C.: An extended and improved Special Sensor Microwave Imager (SSM/I) period of record, J. Appl. Meteorol. Clim., 49, 424-439, 2010.

Sheffield, J., Goteti, G., and Wood, E. F.: Development of a 50-year high resolution global dataset of meteorological forcings of land surface modeling, J. Climate, 19, 3088-3111, 2006.

Paloscia, S., Macelloni, G., Santi, E., and Koike, T.: A Multifrequency Algorithm for the Retrieval of Soil Moisture on a Large Scale Using Microwave Data from SMMR and SSM/I Satellites, IEEE Trans. Geosci. Remote Sens., 37, 79-93, 2001.

Solomon, S., Qin, D., Manning, M., Alley, R. B., Berntsen, T. Bindoff, N. L., Chen, Z., Chidthaisong, A., Gregory, J. M., Hegerl, G. C., Heimann, M., Hewitson, B., Hoskins, B. J., Joos, F., Jouzel, J., Kattsov, V., Lohmann, U., Matsuno, T., Molina, M., Nicholls, N., Overpeck, J., Raga, G., Ramaswamy, V., Ren, J., Rusticucci, M., Somerville, R., Stocker, T. F., Whetton, P., Wood R. A., and Wratt, D.: 2007: Technical Summary. Climate Change 2007: The physical science basis. Contribution of working group I to the fourth assessment report of the intergovernmental panel on climate change, edited by: Solomon, S., Qin, D., Manning, M., Chen, Z., Marquis, M., Averyt, K. B., Tignor, M., and Miller, H. L., Cambridge Unversity Press, 2007.

Su, Z., Yacoba, A., Wen, J., Roerink, G., He, Y., Gao, B., Boogaard, H., and van Diepen, C.: Assessing relative soil moisture with remote sensing data: theory, experimental validation, and application to drought monitoring over the North China Plain, Phys. Chem. Earth, 28, 89-101, 2003.

Su, Z., Wen, J., Dente, L., van der Velde, R., Wang, L., Ma, Y., Yang, $\mathrm{K}$., and $\mathrm{Hu}, \mathrm{Z}$.: The Tibetan Plateau observatory of plateau scale soil moisture and soil temperature (Tibet-Obs) for quantifying uncertainties in coarse resolution satellite and model products, Hydrol. Earth Syst. Sci., 15, 2303-2316, doi:10.5194/hess-152303-2011, 2011.

Van der Velde, R. and Su, Z.: Dynamics in land-surface conditions on the Tibetan Plateau observed by Advanced Synthetic Aperture Radar (ASAR), Hydrolog. Sci. J., 54, 1079-1093, 2009.

Van der Velde, R., Su, Z., and Ma, Y.: Impact of soil moisture dynamics on ASAR signatures and its spatial variability observed over the Tibetan Plateau, Sensors, 8, 5479-5491, 2008. 
Van der Velde, R., Su, Z., Ek, M., Rodell, M., and Ma, Y.: Influence of thermodynamic soil and vegetation parameterizations on the simulation of soil temperature states and surface fluxes by the Noah LSM over a Tibetan plateau site, Hydrol. Earth Syst. Sci., 13, 759-777, doi:10.5194/hess-13-759-2009, 2009.

Van der Velde, R., Su, Z., Van Oevelen, P., Wen, J., Ma, Y., and Salama, M. S.: Soil moisture mapping over the Central Part of the Tibetan Plateau using a series of ASAR WS images, Remote Sens. Environ., 120, 175-187, 2012.

Wagner, W. and Scipal, K.: Large-scale soil moisture mapping in western Africa using the ERS scatterometer, IEEE Trans. Geosci. Remote Sens., 38, 1777-1782, 2000.

Wagner, W, Naeimi, V., Scipal, K., de Jeu, R. A. M., and MartínezFernández J. L.: Soil moisture from operational meteorological satellites, Hydrogeol. J., 15, 121-131, 2007.

Wang, J. R. and Choudhury, B. J.: Remote-Sensing of Soil-Moisture Content over Bare Field at 1.4 Ghz Frequency, J. Geophys. Res.Ocean. Atmos., 86, 5277-5282, 1981.

Wen, J., Su, Z., and Ma, Y. M.: Determination of land surface temperature and soil moisture from Tropical Rainfall Measuring Mission/Microwave Imager remote sensing data, J. Geophys. Res.-Atmos., 108, 4038, doi:10.1029/2002jd002176, 2003.

Wen, J., Jackson, T. J., Bindlish, R., Hsu, A. Y., and Su, Z.: Retrieval of soil moisture and vegetation water content using SSM/I data over a corn and soybean region, J. Hydrometeorol., 6, 854-863, 2005.

Wu, G. X., Liu, Y., Wang, T., Wan, R., Liu, X., Li, W., Wang, Z., Zhang, Q., Duan, A., and Liang, X.: The influence of mechanical and thermal forcing by the Tibetan Plateau on Asian climate, J. Hydrometeorol., 8, 770-789, 2007.
Xu, X. D., Shi, X. Y., Wang, Y. Q., Peng, S. Q., and Shi, X. H.: Data analysis and numerical simulation of moisture source and transport associated with summer precipitation in the Yangtze River Valley over China, Meteorol. Atmos. Phys., 100, 217-231, 2008.

Yanai, M. and Wu, G.-X.: Effects of the Tibetan Plateau. The Asian Monsoon, edited by: Wang, B., Springer, 514-549, 2006.

Yang, K., Ye, B., Zhou, D., Wu, B., Foken, T., Qin, J., and Zhou, Z.: Response of hydrological cycle to recent climate changes in the Tibetan Plateau, Clim. Change, 109, 517-534, 2011 a.

Yang, K., Guo, X., He, J., Qin, J., and Koike, T.: On the Climatology and trend of the atmospheric heat source over the Tibetan Plateau: An experiments-supported revisit, J. Climate, 24, 15251541, $2011 b$.

Yang, K., Ding, B., Qin, J., Tang, W., Lu, N., and Lin, C.: Can areosol loading explain the solar dimming over the Tibetan Plateau?, Geophys. Res. Lett., 39, L20710, doi:10.1029/2012GL053733, 2012.

Zhang, X., Ren, Y., Yin, Z.-Y., Lin, Z., and Zheng, D.: Spatial and temporal variation patterns of reference evapotranspiration across the Qinghai-Tibetan Plateau during 1971-2004, J. Geophys. Res., 114, D15105, doi:10.1029/2009JD011753, 2009.

Zhong, L., Ma, Y., Salama, M. S., and Su, Z.: Assessment of vegetation dynamics and their response to variations in precipitation and temperature in the Tibetan Plateau, Clim. Change, 103, 519535, 2010. 